\title{
Narratives of Spatial Division: The Role of Social Memory in Shaping Urban Space in Belfast
}

\author{
Clare Mulholland, Mohamed Gamal Abdelmonem and Gehan Selim \\ School of Architecture, Planning and Civil Engineering, Queen's University Belfast, Belfast BT9 5AG, UK
}

\begin{abstract}
The paper examines the role of shared spaces in divided cities in promoting future sustainable communities and spaces described as inclusive to all. It addresses the current challenges that prevent such inclusiveness and suggests future trends of its development to be of benefit to the wider city community. It explains how spaces in divided cities are carved up into perceived ownerships and territorialized areas, which increases tension on the shared space between territories; the control of which can often lead to inter-community disputes. The paper reports that common shared space in-between conflicting communities takes on increased importance since the nature of the conflict places emphasis on communities' confidence, politically and socially, while also highlighting the necessity for confidence in inclusion and feeling secure in the public domain. In order to achieve sustainable environments, strategies to promote shared spaces require further focus on the significance of everyday dynamics as essential aspects for future integration and conflict resolution.
\end{abstract}

Key words: Divided cities, shared space, community integration, social behavior, urban design.

\section{Introduction}

The structure of the contemporary city resonates in forms and systems of communications within a spectrum of spaces, physical, social and virtual, as spaces of appearance that ascribes individuals to shared interest and debates of society [1]. Whether these spaces are materialistic production of capitalist ideologies or as instruments of coercion and violence on issues of inequality in ethno-national conflict, they stand as vital platforms of engagement where members and communities of that structure negotiate the merit of their membership within society [2]. According to Henri Lefebvre, it is through the negotiation with space, individuals carve their right to the city and therefore such structures constitute its urban condition. Through spatial reforms, restructuring territories and place regenerations, planners and politicians attempt to confront the status-quo in cities whose structure is chiefly contested amidst the ethno-national divide [3].

Corresponding author: Gehan Selim, lecturer, research fields: architecture, place-making and urbanism in contested spaces. E-mail: g.selim@qub.ac.uk.
For the divided city to escape its wounded fate and overcome its problems, the image and identity of its spaces need to be redefined into liberal and modern forums of the "new" to contrasts with the "old" that sometimes is superficial [4]. However superficial this may be, cities with divisions tend to invest heavily, according to Lee [5], in efforts to "normalize" or "neutralize" their problems of social truncation and political polarization that fail to fade away.

Officials and planners used the term "shared space" as an attractive coin that contrasts with the "ethnic norms" and promotes alternative venues of integration with different social and spatial outcomes [6]. Shared spaces, by definition, ascribe space to certain social prerequisites and modes of interactions in a quest to help heal inherited wounds of sectarianism [7]. As anticipated forums of socio-political engagement, they are designed to recognize memories and histories of a forgettable past, with realization of responsibility towards a shared and imagined future within the urban context. Nevertheless, the city shared spaces have been victims to the human struggle; class, race, gender, and 
religious disunions which created divisions of varying severity. Some strategies have their own woeful long-term consequences of transforming divisions from ethno-political to socio-economic. To neutralize national/ethnic identities, planners introduced themed quarters of cultural, economic or touristic nature, which, whilst used by different groups, contributed to the neo-liberal socially exclusive agendas, raising multiple questions on the notion of "shareness" in the first place [6].

The conception of sharing in northern Ireland is based on the logic of struggle over rights and territorial claims, trying to refute it using its extreme opposite; spatial embodiment of neutrality in the use of public space [8]. Sharing space, however, does not necessary entail unified and neutral culture. But its positive engagement necessitates opportunities for self-expression, negotiations and contestation of identities in non-violent ways [9]. The introduction of cultural or themed quarters, business districts in post-conflict cities, whilst alienating sectarian divisions in these zones, reproduced a neo-liberal ideology of gated enclaves that even though not fenced off, remain largely inaccessible to ordinary citizens due to associated affordability and involved cost of being there. Such capital-driven restructuring is thought to attract new investment in the property economy to challenge spatial sectarian inefficiencies and hence ethnic structures become less relevant [3]. It could, hence, be argued that these areas have accumulated an alien identity that is largely irrelevant to the everyday lives of the ordinary citizens. They, in most cases, are limited to certain occasions or seasonal visits, such as cultural nights and family holidays. According to Murtagh [3], urban areas have been characterized by re-segregation, during comprehensive efforts and processes of desegregation, whereby new socially segmented spaces simply overlie stubborn patterns of racial segregation.

This paper aims to examine how the notion of shared space in Belfast was redefined in designing public services buildings located on the borderline in interface zones, in areas where strategies of shared space in northern Ireland have been deliberately delayed. The discrete evidence is that, whilst projects of themed identity flourished in northern Ireland, the number and areas of peace lines and separation barriers intensified in residential areas following the Good Friday Agreement in 1998. It could be hypothesised that ideas of "shared spaces" were utilized either for actual conciliation or to facilitate political agendas for neoliberal urban transformation of the city. However, policies and strategies of "shareness" were largely questionable and did not contribute much to change of attitude in areas that affect the lives of the ordinary citizens. This paper therefore highlights how "designed space" in borderline areas were sites of a coerced agency of conciliation, between the front lines of everyday interaction and those of an elitist nature. The argument is that notions of "shareness" need to be embodied in these projects as a means of persuasive choice for everyday needs rather than superimposed in top-down strategies that take for granted its imagined socio-spatial success. The paper embarks on a theoretically-grounded discourse on the effective use of shared space in divided cities, then brings this discourse to the realities of everyday contentious life in the border areas in Belfast.

\section{Shareness and Division in the Public Space}

Urban theorists argue that modern cities are accustomed to segregation in one way or another. Grounded in fragmentation, polarization and division, the notion of division is experienced and clearly visible in urban structural complexity as a precondition of being a city. It is part of their challenge and what shapes their identity and condition for being modern and for being urban [10]. For cities with the "divided" prefix, such as in Jerusalem, Nicosia, Tripoli, Belfast and Beirut, the outcomes are exacerbated through physical and social polarization that is evident in everyday social exchange between 
different population groups: inhousing, education, workplace, and cultural and social practices [7]. It cognitively occurs simultaneously at every level of interaction and spatial expressions with the very use of the term "the other side" allowing communities to live "parallel lives that often do not seem to touch at any point" [11]. In such insular forms, myths about the "other side" prosper, provoking imaginable fear and reducing the desire for intercommunity engagement, as shown in Fig. 1.

Myths are products of popular culture that cognitively communicate coherent social positions, norms or even fears. When attached to buildings and/or structures, they become powerful tools of collective memory of the group [12]. In post-conflict cities, buildings and spaces fulfill a substantial role in the cognitive landscape of the urban experience. The peace lines and gates between communities are the most powerful tools of division, by the very fact of their existence. Nevertheless, they hold positive connotations of reminding rivals about forgetting old times, whether for good or bad, leaving behind their physical manifestations: buildings and spaces. They remain reminiscences of bad events that cannot magically embody memories by virtue of their existence, without continuous and sustainable performance of acts, rituals and normative social behavior [13].

But why, in conflict cities, is the notion of shareness seen as a difficult resolve, despite being the norm in the public structure of the urban landscape. For urban living to be based on shared services and resources, the notion of division is a consequence of events, incidents or experiences that asserts inequality, on ethnic, religious, political, social, economic or racial grounds. It causes an "increasing inequality of neighborhood resources and services, the escalating price of decent housing, the ever widening income gap between rich and poor, and the dismantling of the legislated safety net leaving families homeless" [14]. Constructed on the basis of fear of the "privileged other" and sense of vulnerability and insecurity in an unfair system, the agency of the locality asserts its grip on the powerful social institution of communities. In fact, the state's failure to fulfill its moral obligations towards vulnerable individuals opens up opportunities for other societal forces to move in and fill this power void.

Hence, calls for a plural society, in which each individual has equal rights to the city and its spaces, without the mediating agency of groups, pose a serious threat to social structures that have filled large void in solidarity and social support, which was not possible during the conflict years. The structure of division has hence been ingrained in the very existence of each community, seen by many as a matter of survival rather than choice. But, as a recognized city, urban landscape must respond to the needs of diverse groups, of majority/minority interests and practices. So, why should the practice of division be more prevalent than the notion of shareness in a city, despite the short history of the former compared to the latter? To answer this question, let us explore the epistemological connotations of both terms within the construction of contemporary society in order hopefully to clarify some the contingent consequences of the condition of conflict.

One reading of the city is that it is a hub of infrastructures on which urban living is layered into buildings, spaces and domains of socio-political and economic interaction. The credibility of a space stems from its accessibility and openness to the needs of different groups. City spaces are hierarchical and structured out of political importance, from the formal, city council, government, or parliament spaces that celebrate and confirm democracy, to the most private spaces of the residential quarters, where the state withdraws and mutual integration within locality thrives. While the former relies on collective confidence in elected institutions, the latter works on mutual interests of fellow residents that develop through everyday interaction. 


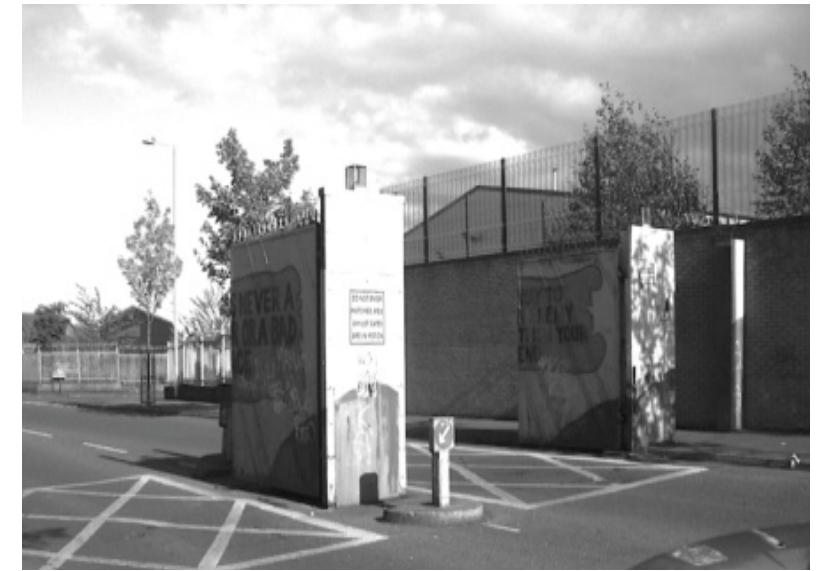

Fig. 1 A gate through the peace wall areas between the Springfield Road and the Shankill Road in Belfast.

Hence, the practice of shareness goes unnoticed as the everyday norm of living in the collectively owned city spaces. Public space is what perhaps underlines this notion of shareness and equal access to the city spaces. This practice goes on for centuries, with decades of struggles, scarcity of resources, political or colonial struggles, etc.. Therefore, living in the city, essentially confirms the precondition of accepting the giving up of part of what otherwise would be exclusively yours; in other words, accepting equal access to others.

Structures and institutions of division develop spatial enclaves that assert their authority and define their boundaries in physical and spatial terms. Similar to the state, the sovereignty of institutions of division requires physical boundaries that define authority lines. Nothing could be more obvious than the walls built in extreme conditions of division in Belfast, Cyprus, and the Jerusalem/West Bank, all of which were nurtured on the vulnerability of propagated fear of the other. In Belfast, recent calls for a pluralist city and equal rights to public space remain of little if any relevance to individuals who have grown up in the confines of institutionalized division, as long as the conflict condition remains intact. Neutralization of these microstructures and their spatial consequences can only ensue from a restored confidence in the collective management of the city as equal for everyone.

\section{Division, Space and Intergenerational Memory}

Conflict stemming from ethnic, national, or religious polarization is a common feature of the contemporary city, while ethno-national division is what make certain cities unique in their condition of division and hence interesting to urban theorists. In such condition, citizens "co-exist in a situation where neither group is willing to concede supremacy to the other" [15]. More critical is the manner with which psychological barriers develop out of this divide to inform individual perception of space, and disrupt ones' spatial reading of the city, who becomes locked in coping strategies as instant reaction to anticipated danger. Resultant mental maps may be based on personal experience and/or community-knowledge but they reproduce such negative reading of the public space through decision-making and public policies, and everyday use of space [16]. The presence of physical, visual and psychological barriers, hence, asserts an urban condition of continuous insular pattern that hinder possibilities of accidental communication or positive intercommunity engagement.

Here, it is worth looking at the influence of space and buildings on the behavior of individuals in divided territories. Theorists and sociologists like Maurice Halbwach stress that individuals' memory is indelibly inscribed in space, with strange potential for spatial memory that conjures up a dense web of images and events that are localized in areas adjacent to homes [17]. For material culture theorists, our memories could be transferred to solid material objects, by way of symbolizing memories or capturing narratives of history, which by virtue of their durability preserve them in perpetuity [18]. But, memory requires stories and narratives that give meanings to the spaces within which these events or incidents took place [19]. Societies and groups retain their collective memory through continuous and sustainable performance of acts, rituals and normative social behavior [20]. Whether it belongs to history or engages with everyday 
practice of living "it is about the desire for remembering or the fact of forgetting" [12]. One form is the very existence of the separation as a wall, fence, or a barrier building. The sense of being divided connotes to the meaning of being protected.

Part of such prejudice towards the other is where young generations are uprooted and educated in the same physical setting that witnessed horrible past and previous experience of violence. Collective memory in this condition develops a mind-set of layered events that correspond to a specific place, time and people, asocial performance [21]. Knowledge of the past shapes the guidelines by which present activities and living conditions are measured and appropriated, and such social performance in events like parades are best seen to keep this memory alive [12]. While every generation has a distinctive sense of the past, people view their space-story history through the proximity of everyday remembrance of the lost ones, which gives prominence to the negativity of the conflict over the "shareness" of the society's coexistence in the present and future.

\section{Spatial Strategies of Shareness in the Public Space}

Alongside the social implications of insular community activity, financial implications of division in northern Ireland were vastly high seen in the cost of segregation of communities services and facilities, which was estimated to amount to $£ 1.5$ billion per annum during 2004-2005 [22]. From a typological point of view, spaces of divided city are generally territorialized, neutral, shared, cosmopolitan or corporate spaces. In fact, the condition of Belfast as a post-conflict city is theoretically debatable, as this would confirm an end to the conflict condition, which is yet to be practically accepted.

A rejuvenated vision of public space in northern Ireland seems to escape this state of conflict, recognizing the precondition of diversity as a democratic space that is not neutral but open, non-hostile, "a place where different forms of cultural heritage can be expressed in an environment that is safe, welcoming, good quality and accessible for all members of society" [23]. That space is free from territorial and sectarian claims, a space that is impartial, free from barriers and accommodates differences, but not hostility [24]. McKeown et al. [25] categorize three types of shared space in the divided context in northern Ireland: the first is "naturally shared environments", everyday melting pots; the second is "policy driven shared environments", where spaces are created as deliberate shared spaces such as integrated schools; and thirdly, "field interventions", which are generally short term projects; for example, cross community programmes. This classification could be equally applied to other cities with simple terms as "public space", "planned space" and "regenerated areas". Yet, it seems that the terms "shared" and "intervention" are forcefully superimposed to deliver on the political image of "post-conflict reality".

As a new capitalist city, neo-liberal philosophy of economic-led resolution to conflict attempts to transform the city into a capitalist centre, where foreign investment is injected into signature projects and thriving job markets would be the only outcome [26]. The Titanic Quarter and Lagan Side Developments to the north east of the city emerged as successful examples of a new cultural of business quarters on the basis of a smart economy and smart jobs resulting in similar exclusive spaces of high profile users. This has limited the impact on the socio-economic conditions of adjacent communities and neighbourhoods, whose residents lack high-end qualifications required for these jobs, leaving them feeling left out. It also represents a mismatch between the needs of spatial economy of engagement and the exclusive nature of the created spaces to which the unskilled, unqualified classes have no access, turning new spaces intimidating to those affected by the troubles [2]. In contrast, these public spaces of neo-liberal settlements introduced an alternative space for the others; a workforce of 
strangers who are alien to the conflict as well as alien to the communities themselves. The Capitalist city, in this instance, created spaces that are far more removed from people and society than they do with the conflict itself, as shown in Fig. 2.

Similar to the business quarters, cultural quarters, that were developed to capitalize on the traditional, cultural or even political assets of the city, remained branding strategies for tourism, rather than catalyst projects for engagement with the city's public spaces as central to the notion of being shared [3]. Thriving on seasonal occasions and cultural nights, where free admission is granted, those quarters witness limited if any meaningful spatial practices throughout the year. The Cathedral Quarter, for example, is largely disconnected from surrounding communities by a series of giant civic buildings housing specific businesses (St. Anne's Square development), city centre shopping centres and high street outlets, or by the University of Ulster campus, all of which cease to operate after 6 p.m.. Such settings deprive the series of interlocking lanes and alleyway spaces from being viable and active spatial routes of social engagement, necessary to the area's security, safety and sociability. To a large extent, this limited vision of branding, neo-liberal capitalism, and physically led regeneration projects overlooks substantial prerequisites for these spaces to thrive as living organisms [5]. The social logic of the generated spaces, in Henri Lefebvre's terms, is missing, with neither the layered activities nor possibilities of engagement that would allow these public spaces to act as mediating veins of continuous socio-spatial pulses among active residential districts.

Spatial practices enabled by those open, modern spaces of the new zones, remained largely different from those inherent in the city's built fabric and urban culture. City spaces require certain knowledge of the local culturally accepted norms of behavior. There is a social code of accepted norms about how one should behave in public spaces, such as streets, squares and parks, and "defying this code is to make a tiny, stinging cut in the social contract" [26]. Stevenson [27] expands on this understanding and relates it to expression of personal identity and action, stating that the expression of an individual's identity, social behavior and actions is influenced by the context of the space they inhabit, that is, an individual will modify their behavior and actions to what they deem appropriate for their surrounding context.

Between individual liberty and the collective social contract, public spaces could be measured against their capacity for being shared or exclusive. For example, an insular residential neighborhood would enforce a code of conduct for local streets. Hence, the understanding of such context in relation to individual expressions of identity can contribute to conflict resolution, as "different understandings of space can not only facilitate different ways of expressing and regulating identity, but also potentially facilitate coexistence between opposing groups" [27].

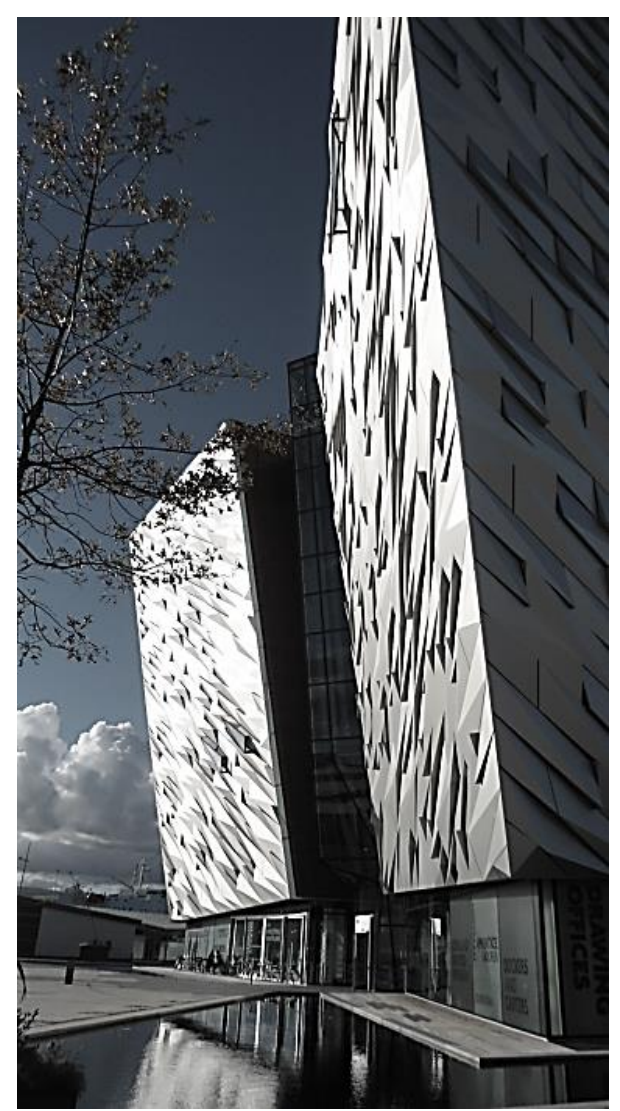

Fig. 2 The Titanic Quarter large-scale waterfront regeneration project in north east Belfast. 
Gaffikin et al. [28] argues that public spaces provide activity space for mixing and learning about other traditions through chance encounters which can "help break barriers", and potentially contribute to "reconciliation and integration", through creating room for "unexpected or surprise encounters, and illustrate both the potential and challenges of having a less segregated city" [29].

\section{Investigating the Intangible Condition of the Interface Area in Everyday Practice}

Northern Ireland has officially been on ceasefire since 1994, and despite experiencing considerable political development, residential segregation remains as a significant and costly problem, especially in the vicinity of interface areas. "The impact on relationships, labour markets, the inefficient use of services and facilities, significant urban blight and poverty are all characteristics of divided areas" [30]. To understand the significance of public spaces and services, one just needs to refer to the 2001 census for Belfast, which shows that $70 \%$ of the population live within an area that is highly polarized, defined as a place that is at least $81 \%$ Catholic or Protestant, while a small percentage, $10.7 \%$ of Catholics and $7.0 \%$ of Protestants, live in mixed communities. Such polarization is higher in working class areas and areas of social housing with scarcity of access to shared public services and resources [31]. With $91 \%$ of social housing estates under control of the NIHE (Northern Ireland Housing Executive) and polarized by religion and community background, NIHE estates in Belfast display more substantial segregation, driven by the urban context, than elsewhere in northern Ireland.

A key difficulty with territorial ownership in such a divided urban landscape is that new land cannot be created, therefore land cannot be "won" unless there is a perceived "loss" to the other side. This cognitive tension places emphasis on the shared space between territories, the control of which can often lead to inter-community disputes, that as a consequence generates further future socio-spatial exclusion [32]. This exclusion provides a framework for further fear, segregation and social representation, which can be visible in everyday interaction in the public space and through the spatial expression of residential segregation. Separation and insular community behavior can have a circular damaging effect, as myths can prosper about the "other side", which in turn can increase fear and reduce the desire for future integration, as shown in Fig. 3.

In contrast to the negative effects of population separation, everyday mixing and encounters in social spaces contribute to an individual's understanding of diversity. The lack of interaction between population groups in common spaces contributes to a "mutual lack of information" about those we live with [33]. Continual negotiation of diversity occurs, chiefly, through the local "micro-politics" of everyday interaction between individuals and groups. While acknowledging "habitual contact in itself is no guarantor of cultural exchange", mixing individuals in shared environments with shared activities trains them to overcome fear of the stranger and "disrupts easy labelling of the stranger as enemy and initiates new attachments" [9].

Anticipated change, hence, is tested through the social dynamics and everyday practices in mixed neighborhoods, workplaces, schools, leisure sites, and public spaces. This micro-politics of the everyday

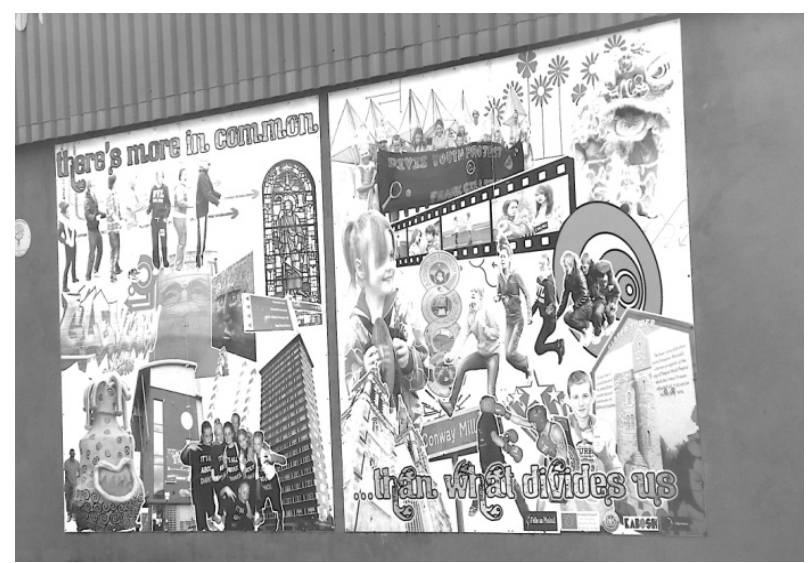

Fig. 3 Peace walls in Belfast illustrating notes of division "There is more in common than what divides us". 
offers a valuable form of contact with the opportunity for informal exchanges or marginal encounters with others in an undemanding casual manner, which can create positive experiences and may lead to other high intensity interactions: "these modest 'see and hear contacts' must be considered in relation to other forms of contact and as part of the whole range of social activities, from simple and noncommittal contacts to complex and emotionally involved connections" [34]. Daily interaction and presence within crowds builds "studied trust" and shared perspectives in urban multiplicity. This increased trust and integration can build a sense of shared society, and "feeling safe and secure in a space is a vital precursor to fostering trust and encouraging new uses" [35].

In the divided context, it is argued that the provision of space for mixing and chance encounters can support reconciliation and integration, and the positive actions of this mixing can create room for unexpected or surprise encounters, and illustrate both the potential and challenges of having a less segregated city. Key factors impacting on inclusivity are discussed separately/individually in the terms of "territorial ownership": between the physical and physiological, spatial economy and urban regeneration, discursive condition of the inaccessible city and The micro-politics of the everyday contact.

\subsection{Territorial Ownership: Between the Physical and Physiological}

Entrenched in the history of Belfast since its foundation, residential segregation has rendered the city a land of territories. People are born, educated, medically treated and buried in the same locations as their ancestors, a culture of reproduction of division. Limited accessibility to border areas reduces mobility freedom and produces patterns of spatial intimidation through community surveillance. Territorialisation is a practice, rather than an imposed pattern, that generates a set of barriers which are either physical, in terms of walls and barriers, visually represented through flags and emblems, or physiological in terms of use of space or mental mapping.

The erection of physical barriers has been used as a technique to stop or reduce tensions between the parties, as seen in cities such as Nicosia, Mostar, Beirut and Belfast. From manual handling of temporary materials to permanent walls of up to $14 \mathrm{~m}$ in height, these barriers emerged as substantial signifiers of the spatial experience in Belfast and a remarkable landmark in the urban landscape. The most prominent of these "peace lines" is located in west Belfast, dividing the nationalist Falls area from the unionist Shankall area. It is $800 \mathrm{~m}$ long and a notable $10.8 \mathrm{~m}$ in height and was built in 1969 as an "act of desperation" by a community which was exposed to extreme situations [36]. At that time, these partitions immediately reduced the threat of violence and by so doing, justified the paranoia and fear of the "other side", leading to communities developing behind the walls with a stereotyped fear of the "unknown other", with "toxic" effects on social coexistence that have multiplied ever since. This form of physical separation is typically a hindrance and chronic obstacle to normalization between communities [37]. With a reported 99 physical barriers across the city, one third of which have been constructed since the ceasefire, it is evident how diverse and interweaved the city's communities are, and how entrenched in everyday practice of many inhabitants, the notion of division is.

Visual markers such as flags, murals, painting of kerbstones and lampposts are further territorial indicators that are used as means of expression of cultural identity and a statement that communities have a "right" to such expression. In fact, "everyday spatial behaviour of people in northern Irish towns and cities is dictated by the demarcation of public space through flags, murals and kerbstone painting". The failure of the US-led political process in December 2013 to agree a deal on flying the Union flag over City Hall, following almost daily protests since December 2012, is a testimony on the continuing significance of flags as 
a symbol of community identity [38].

Physiological barriers are maps of fear that destabilize the popular perception of space of individuals, who develop "coping strategies" to help them avoid perceived danger. In doing so, people create physiological barriers and mental maps of spaces to determine safe routes to use, mainly through personal experience and/or knowledge from their community group, and these guide decisions on the use of space. These are passed down through generations which in turn reproduce similar spatial patterns and navigation strategies in their everyday practice while contributing to the conditions of conflict and perpetuating the cycle. It is this insularity which contributes to the lack of positive inter-community relationships, which in turn can be an obstacle to shared space [39].

\subsection{Spatial Economy and Urban Regeneration}

There is a credible argument that processes of privatization and commercialization have compromised access to public space and increase in stratified societies. Murtagh [3] argues that the new wave of urban regeneration appealed to Belfast in the form of new workplaces and dwellings that would allow a break from existing ownership structures as they were seemingly free from sectarian claims; they were classed as "neutral" or "corporate" space, opposed to carrying traditional "Protestant" or "Catholic" territory classification. Adopting new imagery through low risk, glitzy and speculator sites was key to new place marketing as a bid to attract new investors and tourists to the city. However, some argue that such new city centre regeneration projects are alienating and members of working class communities are excluded from these developed areas. Within the city, the Titanic Quarter, which is a recent high profile regeneration project, is cited as a poor example of the creation of open shared space in the city as the increased privatization and commercialization has led to a compromised public realm that can limit inclusion to members of the Belfast community through social inequality and economic divides. In a counter argument, however, Iveson [40] stresses that there is no such loss to public life; the publicness that we are supposed to have lost is in fact a "phantom", never actually realized in history but haunting the frameworks for understanding the present.

Kelly [41] criticizes the neo-liberal economic approach to this form of development and highlights the irony that despite the significant amount of public money invested in the creation of the Titanic museum, because of the price of entrance tickets most families from working class areas are excluded from visiting it. Being remotely located on the city's peripheries, the Titanic Quarter needs to offer a series of destinations for public use and enjoyment that would encourage families and young people to make the necessary long journey. In contrast, being restricted to a museum with entry fees and neighboring commercial facilities and shopping centres, there are arguably no spaces for average working class families to engage with. Generated public spaces, therefore, remain isolated from the spatial everyday systems of the city of the working class, denoting these gentrification projects as isolated and another exclusive territory.

From another viewpoint, this was just a normalisation of Belfast as a modern city, whose public spaces are reliant on private investments of corporations and their requirements in a spatial form of capitalism. Murtagh [3], for example, states that "in reality, Belfast has caught up with the neo-liberalization of the urban space familiar in other late capitalist cities but in more selective and potential unstable ways". There is no more obvious sign of such forms than the series of bank buildings surrounding Belfast City Hall, with overly protective and inaccessible ground floor facades as a measure of security for invested capital. While justified on security grounds, such a spatial experience leaves the space intimidating and somehow disengaging. In fact, public space in Belfast city centre serves three mutual aspects: 
(1) facilitating processes of capital exchange based on commercial and financial communications, through well-designed spatial systems; (2) minimizing security risks to establishments; (3) avoiding direct links between the two communities and the city centre spaces. The labyrinth of streets and access routes around Castle Court shopping centre has been carefully designed to avoid such direct outdoor paths between its front and rear facades.

Similarly, Writers Square, a supposedly well located and designed public space opposite to the historic St. Anne's Church, appears to be quite intimidating. Although the surrounding buildings, such as those located on William Street and Church Street, attempt to display a relationship with the public square, they fail to do so. Many of the businesses formally occupying ground-floor units have been closed down and/or relocated, replacing lively public space edges with a defensive border, consisting of graffiti-stained shutters. Furthermore, lining one edge of the public square is the Police Ombudsman building, a large-scale office building. Again, the ground-floor facade is blocked off to prevent any possible engagement with pedestrian passers-by. This space fell victim to its location on such edges of conflict, a border area per se.

\subsection{Discursive Condition of the Inaccessible City}

The accessible and connected city is, unsurprisingly, to remain as the main strategic objective of the new Masterplan for Belfast (2012-2015), with focus on "enhancing accessibility and connectivity internationally, regionally and locally" [42]. While the relationships between segregation, physical and social inequalities are intertwined; urban segregation can be considered the spatial manifestation of social polarization of the population. Groups living in segregated communities experience limitations on access to most of their local publicly funded services. Shirlow and Murtagh [30] found that 78\% of Belfast's population did not use their nearest public facilities because they were located on the "wrong side" of the community boundary, with over $75 \%$ of individuals failing to use their local health centre for the same reason. In the Ardoyne and Upper Ardoyne interface area, $82 \%$ choose not to use the nearest leisure centre, instead opting to travel to a leisure centre in another part of the city to be with their own ethno-national group.

While segregation permeates throughout many of the city's sectors and zones, with more concentration in the northern and eastern sections, it is also divided around "the commuter belt", where much of the economic development is in a series of corridors, such as Titanic \& Harbour, City Centre, and University. The heavy reliance on car transport and clusters of inwardly-focused residential enclaves has led to road network-led voids in the built fabric that generate unfriendly environments for pedestrians and cyclists. With over half of the households in deprived inner city areas having cars, improvements to pedestrian networks need to be made to open up opportunities to create a better-connected city. But, such connectivity is still impeded by social exclusion, pragmatic problems connected to class stratification, with mothers from socially deprived segregated communities being excluded due to absence of economic resources and problems in transporting young children to the area.

Group and individual mobility levels impact on their ability to access, use and hence interact in shared spaces. Gaffikin and Morrissey [43] note that in a number of communities in contact with the city's inner belt there is an "acute relationship between deprivation, residential segregation and violence". This has been heightened by the development of the "win speed city", that evolved with the economic boom, which witnessed groups with skills and education excelling and those without these resources remaining tied to their estates [44]. In absence of qualifications and skills, people become vulnerable to external engagement with others and withdraw more into their locality. This eventually results in a situation whereby "the insularity of segregated communities obstructs the creation of 
shared physical, psychological and organizational space".

Policies on the spatial condition of the shared space in Belfast remain fragmented due to the various departments that deal with such multi-dimensional issues and clear unified definition of shared space is lacking. Relationships between community groups and government agencies are made more difficult by the lack of coherent unified policies, "with the consequence that some policies tend to reinforce separatist lifestyles and segregated spaces" [45]. These problems and poor communication lead to a lack of incentive for community groups to work with public bodies.

In order to realize positive change, governmental initiatives need to be focused on a clear strategy that provides an increased number of shared spaces, which goes beyond the narrow connectivity belt and more towards improving accessibility. This would encourage inter-community tolerance and could thus be a catalyst for change. But, who is the actual owner of the space and de-facto decision maker, the community or the state, or society at large? The ownership of space is, hence, a key feature in ethnic-national conflict, therefore planning of this space may play a role in helping the city heal, "since space is so central to the overall conflict, and planning is the main instrument for social shaping of space, planning is unavoidably central to the conflict's resolution" [28]. This can help break down barriers, and potentially contribute to integration. In order for this interaction to occur, planning policy needs to account for the issue of segregation in zoning policy, land use decisions and transport structures, and in doing so recognize the ways in which individuals' spatial and interaction patterns are affected by ethno-national divides.

Physical urban developments can be used to benefit social cohesion, as development projects could bring together different conflicting groups through the process of discussion and negotiation over a project acting as a means of mediation between the groups. The research group "Planning for Spatial
Reconciliation" in 2012 insists on the need for integrated community collaboration in the planning process as means to improve urban design, as addressing the needs of the community could potentially be an aid to community relations. A positive step towards more community involvement is the introduction of a "duty of community planning" by local councils, due to come into effect in 2015. This will require councils to consult the local community regarding decisions concerning delivering local public services, allowing them the opportunity to engage with projects that will impact on their everyday lives. While this is hailed as a constructive move, and welcomed by the Institute of Royal Town Planners Northern Ireland, they have expressed concern about the lack of detail in the associated Planning Bill regarding the relationship between community and the new planning process, highlighting that an interactive relationship is key to success and needs to be fully considered in order to avoid further community fragmentation in governance of its delivery.

\subsection{The Micropolitics of the Everyday Contact}

Typically overlooked by politicians and strategic planners alike, everyday environments are significant in improving knowledge about the other group, playing down mutual prejudices, and aid integration and community cohesion. It is in these everyday exchanges in public spaces, buildings and services where demonized people could be seen as natural and peaceful human beings. The most frequent everyday inter-community communications take place in public services and the city's shopping and economic base, and in the proximity of everyday homes and domestic environments. Admittedly, it is established in research that no clear line can be drawn dividing public and private spheres [46]. Hence, three different types of shared space accommodate individual and group interactions; first, the traditional or commonly understood sites of shared urban space, that is the square, the piazza, the park, which represent collective 
belonging, where the public have equal spatial ownership rights. The second is representative of social exchange, which occurs on sites existing in the public arena, regardless of their ownership pattern (public or private), yet still allows for social encounters with others (social exchange, discussion and debate). The café and theatre represent those arenas where common performances take place in a physical space, while media and the internet are non-physical forms.

Informal encounters in everyday life describe the third type of shared space, as a de-facto space of shareness, such as the street or on modes of public transport. Gehl's thesis [33] states that such daily interactions in these de-facto spaces of shareness rely on the multiple possibilities to experience the others functioning in various situations, through seeing and hearing them. While such informality is considered a low intensity form of contact, these interactions remain factual in their accord to the individual cognition of the other in an undemanding casual manner; as an equal human being. This creates positive encounters, which possibly lead to higher intensity interactions. These spaces are, in fact, more complex than they first appear: "these modest, see and hear contacts, must be considered in relation to other forms of contact and as part of the whole range of social activities, from simple and noncommittal contacts to complex and emotionally involved connections" [47].

In a way, everyday exchange of "seeing and hearing others" in social spaces contributes to individuals' understanding of diversity; it breaks down the harsh encounters and fears gained at the physical barriers of the interface zones, albeit in other more everyday encounters. The continual negotiation of diversity in everyday interactions, in that sense, could compromise local "micro-politics" of everyday encounters between individual and groups in a quest to overcoming differences: Habitual contact is no "guarantor of cultural exchange"; however, getting individuals to make contact in shared environments with shared activities helps in overcoming fear of the other and develops new attachments. In line with Amin's theory, Lofland acknowledges that "incidental interactions among strangers actually do draw upon and constitute shared meanings, common values and cooperation for collective purposes. People accomplish this by learning, negotiating and reproducing overarching principles for stranger interaction and basic, albeit unspoken, modes of civility" [48]. After all, public space is a place where individuals become aware of others, hence preventing harm caused by "judgements of difference". The process of daily interactions and presence within crowds builds "studied trust" and urban multiplicity that develop a sense of feeling safe and secure that foster trust and encourage development of new uses of further possibilities of exchange [49]. Placing people in living settings where engagement with strangers is a natural process, hence, disrupts easy labelling of the stranger as an enemy and initiates new attachments. Venues of change and intervention, hence, could take place simply through specific design strategies for everyday exchange practices and dynamics for buildings such as workplaces, schools, health centres, leisure sites, public education and nurseries.

\section{Conclusions}

This paper sought to examine the notion and practice of shareness in the public and border spaces in Belfast. Hence, it is seen as legitimate for spatial policy makers to strive for a utopian image of inclusive socio-spatial cohesion and integration, whose achievement would bring divisions and contentious issues in the urban landscape to a sort of compromise. It is inevitable, however, that an intelligible strategy about instilling the perception of coexistence as an everyday reality with equal rights to the city and its spaces is adopted in a win-win situation. Two structural problems emerge here and require further interrogation. First, spatial conciliation in Belfast has to challenge the authority of current society structure, mind-set and way of living as centred on the agency of the group (regardless of who these groups are, or what made them a group in the first 
place). For conciliation to happen, the cognitive trust in the group as agent of the public space is to be contested. Planners desire for educating people to be individualistic and self-centred citizens seems again to repeat top-down authoritative strategies in engineering an image that lacks practicality or achievable targets. For example, the agency of the groups as mediators could be agents of co-existence with role to play in achieving objective realities of the modern city. Meanwhile, capitalist strategies to develop and create new and modern spaces were successful only in restructuring divisions on social basis, leaving working class communities into further poverty and limited opportunities.

The landscape of the city seems to offer a second structural problem, caused by the built environment being constructed intrinsically out of memory and layers of history represented in buildings, streets and spaces. As public spaces emerge between divided landscapes of residential enclaves, they define their respective boundaries in return. The perception of these spaces is, hence, fundamentally territorial, resulting in a non-visual, non-physical fortification of spatial rights and ownership of what is supposed to be shared. These are more evident in integrative parks in interface areas, which, against initial design intentions, were subsequently divided into territories attached to adjacent insular communities. While interface border areas are overloaded with negative experiences and perceptions as territorialized fabric, spaces offer new possibilities for experimentation with spatial relationships of integration. Isolating divisions within its current territories and expanding into new land with glimpses of the pluralist space is emerging as an attractive strategy that is yet to be socially integrative as well as being physically designed. A sequence of new spaces and images of pluralist-Belfast has been mapped into a series of spaces, services and developments and circulated in the media as a promising shared city. The developments expand from city centre eastwards, connecting the harbour, Titanic quarter, City Airport, with the area to the east of the river being prominent in that sense.

While agency of community/group leadership and local support needs to be taken seriously through leadership roles in the new vision of a pluralist space, it must be noted that agency generates defined roles and responsibilities in the local socio-spatial sphere. These include community leaders, local politicians, public servants and other involved actors. Such structural change, from the antagonistic contestation to individual-centric interest in the public space, is a possible reality when sustained neutral socio-economic settings, actually exist. It is problematic, however, whether this can happen within the border areas of interface zones. Spatial systems extending beyond old boundaries and infrastructure of division could be agents of change for progressive non-defensive engagement in a public space. Considering the shortcomings of the neo-liberal strategies, providing social benefits to unskilled working class groups would help new generations be at ease in moving out of territories of division and to have a role to play in the new territories of shareness.

\section{References}

[1] H. Arendt, The Human Condition, University of Chicago Press, USA, 1958.

[2] L. O'Dowd, M. Komarova, Three narratives in search of a city: Researching Belfast's "post-conflict” transitions, City 17 (4) (2013) 526-546.

[3] B. Murtagh, Ethno-religious segregation in post-conflict Belfast, Built Environment 37 (2) (2011) 213-225.

[4] N. Smith, New globalism, new urbanism: Gentrification as global urban strategy, Antipode 34 (3) (2002) 427-450.

[5] A. Lee, Introduction: Post-conflict Belfast City: Analysis of urban trends, Culture, Theory, Policy, Action 17 (4) (2013) 523-525.

[6] G. Jordan, Building space: Regeneration and reconciliation, in: G. Spenser (Ed.), Forgiving and Remembering in Northern Ireland: Approaches to Conflict Resolution, Continuum Publishing, London, 2011.

[7] J. Calame, E. Charlesworth, Divided Cities: Belfast, Beirut, Jerusalem, Mostar, and Nicosia, Philadelphia, University of Pennsylvania Press, Pennsylvania, 2009.

[8] H, Yacobi, The Jewish-Arab City: Spatio-Politics in a 
Mixed Community, Routledge, London, 2009.

[9] A. Amin, Ethnicity and the multicultural city: Living with diversity, Environment and Planning A 34 (6) (2002) 959-980.

[10] M. Leonard, M. McKnight, Bringing down the walls: Young people's perspectives on peace-walls in Belfast, International Journal of Sociology and Social Policy 31 (9/10) (2011) 569-582.

[11] Community Cohesion: A Report of the Independent Review Team, The Cantle report, Home Office, 2001.

[12] M.G. Abdelmonem, G. Selim, Architecture, memory and historical continuity in old Cairo, The Journal of Architecture 17 (2) (2012) 167-192.

[13] P. Connerton, How Societies Remember, Cambridge University Press, Cambridge, 1989.

[14] S.M. Low, Urban fear: Building the fortress city, City \& Society 9 (1) (1997) 53-71.

[15] J. Anderson, From Empires to Ethno-National Conflicts: A Framework for Studying Divided Cities, in Contested States[Online], 2008, http://www.conflictincities.org/PDFs/ WorkingPaper1_5.8.08.pdf (accessed Dec.15, 2013).

[16] N. Jarman, J. Bell, Routine divisions segregation and daily life in northern Ireland, Working Papers, Institute for British-Irish Studies, University College Dublin, Dublin, 2009.

[17] M. Yaari, Rethinking the French City: Architecture, Dwelling, and Display after 1968, Rodopi, Amsterdam, 2008.

[18] A. Forty, Introduction, in: A. Forty, S. Kuchler (Eds.), The Art of Forgetting, Berg, Oxford, 2001.

[19] G.D. Rosenfeld, Munich and Memory: Architecture, Monuments and the Legacy of the Third Reich, University of California Press, London, 2000.

[20] F. Tonkiss, Space, the City and Social Theory, Polity Press, Cambridge, 2005, p. 69.

[21] P. Connerton, How Societies Remember, Cambridge University Press, Cambridge, 1989.

[22] Research into the Financial Cost of the Northern Ireland Divide, Deloitte and Touche, Belfast, Deloitte, 2007.

[23] Good Relations Plan, Belfast City Council, Belfast, 2011.

[24] F. Gaffikin, M. McEldowney, G. Rafferty, K. Sterett, Public Space for a Shared Belfast, Belfast City Council, Belfast, 2008.

[25] S. McKeown, E.D. Cairns, M. Stringer, Is shared space really shared?, Shared Space: A Research Journal on Peace, Conflict and Community Relations in Northern Ireland, 2012.

[26] A. Madanipour, Marginal public spaces in European cities, Journal of Urban Design 9 (3) (2010) 267-286.

[27] C. Stevenson, Beyond divided territories: How changing popular understandings of public space in northern Ireland can facilitate new identity dynamics, Institute for British-Irish Studies, University College Dublin, Dublin, 2010.

[28] F. Gaffikin, M. McEldowney, K. Sterret, Creating shared public space in the contested city: The role of urban design, Journal of Urban Design 15 (4) (2010) 493-513.

[29] Conflict in Cities and the Contested State, Sharing Space in Divided Cities: Why Everyday Activities and Mixing in Urban Spaces Matter, Conflict in Cities and the Contested State, 2012, pp. 1-4.

[30] P. Shirlow, B. Murtagh, Belfast: Segregation, Violence and the City, Pluto Press, London, 2006.

[31] I. Schnell, B. Yoav, The socio spatial isolation of agents in everyday life spaces as an aspect of segregation, Annals of the Association of American Geographers 91 (4) (2001) 622-636.

[32] A. Buonfino, P. Hilder, Neighbouring in Contemporary Britain, Joseph Rowntree Foundation Housing and Neighbourhoods Committee, The Young Foundation, UK, 2006.

[33] J. Gehl, Life between Buildings: Using Public Space, 6th ed., Island Press, Washington, 2011.

[34] H. Lownsbrough, J. Beunderman, Equally Spaced?, Public Space and Interaction between Diverse Communities, Commission for Racial Equality, London, 2007, p. 35.

[35] N. Jarman, Belfast Interfaces: Security Barriers and Defensive Use of Space, Belfast Interface Project, Belfast, 2012.

[36] M. Harbottle, The Impartial Soldier, Oxford University Press, London, 1970.

[37] D. Bryan, C. Stevenson, G. Gillespie, J. Bell, Public displays of flags and emblems in northern Ireland, Working Paper, Institute of Irish Studies, Queen's University Belfast, 2010.

[38] J. Anderson, Political Demography in Northern Ireland: Making a Bad Situation Worse, Political \& Social Significance of the 2001 Census of Population, Centre for Spatial Territorial Analysis and Research, 2004.

[39] B. Murtagh, New Spaces and Old in "Post-Conflict" Belfast, Conflict in Cities and the Contested State[Online], 2008, http://www.conflictincities.org/PDFs/WorkingPaper 5_10.9.08.pdf (accessed Jan. 15, 2014).

[40] K. Iveson, Publics and the City, Blackwell Publishing, Oxford, 2007, p. 6.

[41] B. Kelly, Neoliberal Belfast: Disaster ahead?, Irish Marxist Review 1 (2) (2012) 1-44.

[42] Belfast Master Plan[Online], 2012, www.belfastcity.gov.uk/ masterplan (accessed Dec.22, 2013).

[43] F. Gaffikin, M. Morrissey, Planning in Divided Cities: Collaborative Shaping of Contested Space, Wiley-Blackwell, Oxford, 2011. 
[44] B. Murtagh, Desegregation and place restructuring in the new Belfast, Urban Studies 46 (6) (2010) 1119-1135.

[45] J. Gehl, L. Gemzøe, Public Spaces Public Life: Copenhagen, Danish Architectural, Copenhagen, 2004.

[46] M. Sheller, J. Urry, Mobile transformations of "public" and "private" life, Theory Culture Society 20 (3) (2003) 107-125.

[47] B. Sore, Planning Bill Northern Ireland: A Response by the Royal Town Planning Institute Northern Ireland, Royal
Town Planning Institute Northern Ireland, Craigavon, 2011.

[48] S. Vertovec, New Complexities of Cohesion in Britain: Super-Diversity, Transnationalism and Civil-Integration, Centre on Migration Policy and Society, Oxford, 2007, p. 6.

[49] H. Lownsbrough, J. Beunderman, Equally Spaced?, Public Space and Interaction between Diverse Communities, Commission for Racial Equality, London, 2007. 